\title{
Prediction of repeated intravenous immunoglobulin resistance in children with Kawasaki disease
}

Yaheng Lu, Tingting Chen, Yizhou Wen, Feifei Si, Xindan Wu and Yanfeng Yang*

\begin{abstract}
Background: Repeated intravenous immunoglobulin (IVIG) resistance prediction is one of the pivotal topics in Kawasaki disease (KD). Those non-responders of repeated IVIG treatment might be improved by an early-intensified therapy to reduce coronary artery lesion and medical costs. This study investigated predictors of resistance to repeated IVIG treatment in KD.
\end{abstract}

Methods: A total of 94 children with IVIG-resistant KD treated at our hospital between January 2016 and August 2020 were retrospectively analyzed. According to the therapeutic effect of a second dose IVIG treatment, the children were divided into repeated IVIG-responsive group and repeated IVIG-resistant group, and the clinical and laboratory data were compared. Predictors of repeated IVIG resistance and the optimal cut-off value were determined by multiple logistic regression analysis and receiver operating characteristic (ROC) curve analysis.

Results: The Pre-IVIG laboratory data showed the percentage of neutrophils (N\%) and levels of serum procalcitonin $(\mathrm{PCT})$, N-terminal pro-brain natriuretic peptide (NT-proBNP) were significantly higher in repeated IVIG-resistant group compared with repeated IVIG-responsive group, while levels of serum sodium and albumin (ALB) were significantly lower $(P<0.05)$. The post-IVIG laboratory values of N\% and $C$-reactive protein (CRP) were significantly higher in the repeated IVIG-resistant group compared with repeated IVIG-responsive group, while hemoglobin and ALB were lower $(P<0.05)$. Pre-IVIG PCT and post-IVIG CRP exhibited AUC of 0.751 and 0.778 respectively in predicting repeated IVIG resistance in KD. Pre-IVIG PCT $>1.81 \mathrm{ng} / \mathrm{ml}(\mathrm{OR} 4.1,95 \% \mathrm{Cl} 1.4 \sim 12.0, P<0.05)$ and post-IVIG CRP $>$ $45 \mathrm{mg} / \mathrm{L}$ (OR 4.6, $95 \% \mathrm{Cl} 1.3 \sim 16.2, P<0.05$ ) were independent predictors of repeated IVIG resistance in KD.

Conclusions: Our study illustrates the serum PCT level before initial IVIG treatment and CRP after initial IVIG could be used to predict repeated IVIG resistance in KD.

Keywords: Kawasaki disease, Repeated intravenous immunoglobulin resistance, Prediction

\footnotetext{
* Correspondence: yfyangcd@163.com

Department of Pediatric Cardiology, Chengdu Women's and Children's Central Hospital, School of Medicine, University of Electronic Science and Technology of China, 611731 Chengdu, China
}

(c) The Author(s). 2021 Open Access This article is licensed under a Creative Commons Attribution 4.0 International License, which permits use, sharing, adaptation, distribution and reproduction in any medium or format, as long as you give appropriate credit to the original author(s) and the source, provide a link to the Creative Commons licence, and indicate if changes were made. The images or other third party material in this article are included in the article's Creative Commons licence, unless indicated otherwise in a credit line to the material. If material is not included in the article's Creative Commons licence and your intended use is not permitted by statutory regulation or exceeds the permitted use, you will need to obtain permission directly from the copyright holder. To view a copy of this licence, visit http://creativecommons.org/licenses/by/4.0/ The Creative Commons Public Domain Dedication waiver (http://creativecommons.org/publicdomain/zero/1.0/) applies to the data made available in this article, unless otherwise stated in a credit line to the data. 


\section{Introduction}

Kawasaki disease (KD) is an acute febrile systemic vasculitis syndrome and intravenous immunoglobulin (IVIG) combined with aspirin is the standardized regimen [1]. Approximately 10-20\% of the KD children have a recrudescence or persistent fever at least $36 \mathrm{~h}$ following completion of the first dose of IVIG, which is called IVIG-resistant [2]. Japanese risk-scoring systems are used for predicting IVIG-resistance, but it seems irreproducible outside Japan, and attempts to develop similar algorithms have been unsuccessful in Chinese populations [3]. As yet, treatment of resistant KD remains a challenge that needs to be solved [4].

The mechanism of IVIG resistance is not entirely clear now and maybe related to the putative doseresponse effect of immunoglobulin [5]. A second dose of IVIG at $2 \mathrm{~g} / \mathrm{kg}$ is suggested as the first choice for resistant $\mathrm{KD}$ in current American Heart Association (AHA) guidelines [1]. However, approximately $10 \%$ of KD children might develop to both initial and repeated IVIG resistance [6], and often require additional interventions, such as corticosteroid, infliximab, plasma exchange and cytotoxic agents [7]. An intensified initial rescue therapy may reduce the occurrence of repeated IVIG resistance, but whether apply to every resistant $\mathrm{KD}$ child is controversial when taking into account potential adverse outcomes and the economic cost of the treatment [8-10]. It seems more reasonable to consider intensified therapy if $\mathrm{KD}$ children with repeated IVIG resistance,that have high risk of coronary artery aneurysm (CAA) [11]. Therefore, early identification of repeated IVIG resistance could help physicians make smarter therapeutic decisions to reduce CAA and medical costs. Herein, we performed this study to explore predictors of repeated IVIG resistance.

\section{Materials and methods Study subjects}

From January 2016 to August 2020, 940 children with KD were admitted and managed at Chengdu Women's and Children's Central Hospital, School of Medicine, University of Electronic Science and Technology of China (UESTC). The diagnosis of complete and incomplete KD was established according to the American Heart Association guideline in 2004 [12]. Among them, $112 \mathrm{KD}$ children developed resistance to initial standard IVIG ( $2 \mathrm{~g} / \mathrm{kg} / \mathrm{d}$ for 1 day) therapy. Initial IVIG resistance was defined as recurrent or persistent fever (under-arm temperature $\geq 37.5^{\circ} \mathrm{C}$ ) for at least $36 \mathrm{~h}$ but not longer than 7 days after initial IVIG treatment. Of the 112 initial IVIG-resistant KD children, 9 patients that received steroids as initial rescue therapy instead of a second dose IVIG treatment were excluded, and another 9 children were excluded because of incomplete laboratory data $(n=$ $5)$ or accompanying infectious diseases $(n=4)$. Finally, 94 initial IVIG-resistant KD children were included in the study (Fig. 1).

For 94 KD children with initial IVIG resistance, a second dose IVIG ( $2 \mathrm{~g} / \mathrm{kg} / \mathrm{d}$ for 1 day) was administered according to expert consensus on the diagnosis and treatment of KD in China, and 40 of them developed repeated IVIG resistance. Repeated IVIG resistance was defined as recurrent or persistent fever (under-arm temperature $\geq 37.5^{\circ} \mathrm{C}$ ) for at least $36 \mathrm{~h}$ after the second IVIG administration. At last, the initial IVIG-resistant KD children were divided into repeated IVIG-responsive group $(n=54)$ and repeated IVIG-resistant group $(n=40)$.

This retrospective study was approved by the Ethics Committee of Chengdu Women's and Children's Central Hospital, School of Medicine, UESTC, and with the 1964 Helsinki declaration and its later amendments or comparable ethical standards. The requirement for informed patient consent was waived.

\section{Data collection}

Clinical and laboratory data were collected through medical record review. Clinical data such as age, sex, diagnosis of incomplete $\mathrm{KD}$, time of first and second dose IVIG were collected. Laboratory data on admission pre-IVIG treatment were collected, including white blood cell count (WBC), platelet (PLT), hemoglobin (Hb), percentage of neutrophils (N\%), C-reactive protein (CRP), total bilirubin (TB), serum albumin (ALB), erythrocyte sedimentation rate (ESR), serum alanine aminotransferase (ALT), serum aspartate transaminase (AST), serum sodium $(\mathrm{Na}+)$, serum creatinine, blood urea nitrogen, activated partial thromboplastin time (APTT), prothrombin time (PT), D-dimer, procalcitonin (PCT), N-terminal pro-brain natriuretic peptide (NTproBNP). Laboratory data post-IVIG treatment before the second dose of IVIG including WBC, PLT, Hb, N\%, CRP, ALB, ALT and AST were collected.

The value of coronary artery diameter measured by echocardiography before initial IVIG treatment and at discharge was selected and used to calculate the $\mathrm{z}$ score using the formula by Dallaire and Dahdah [13]. As there is no normal value of coronary artery diameter in Chinese children, CAA was defined as $Z$ score of $\geq 2.5$ in at least one of the following coronary arteries: right, left anterior descending, and left main according to the AHA guideline in 2004 [14].

\section{Statistical analysis}

All statistical analyses were performed using IBM SPSS Statistics ver. 21.0 (IBM Co., Armonk, NY, USA). All 


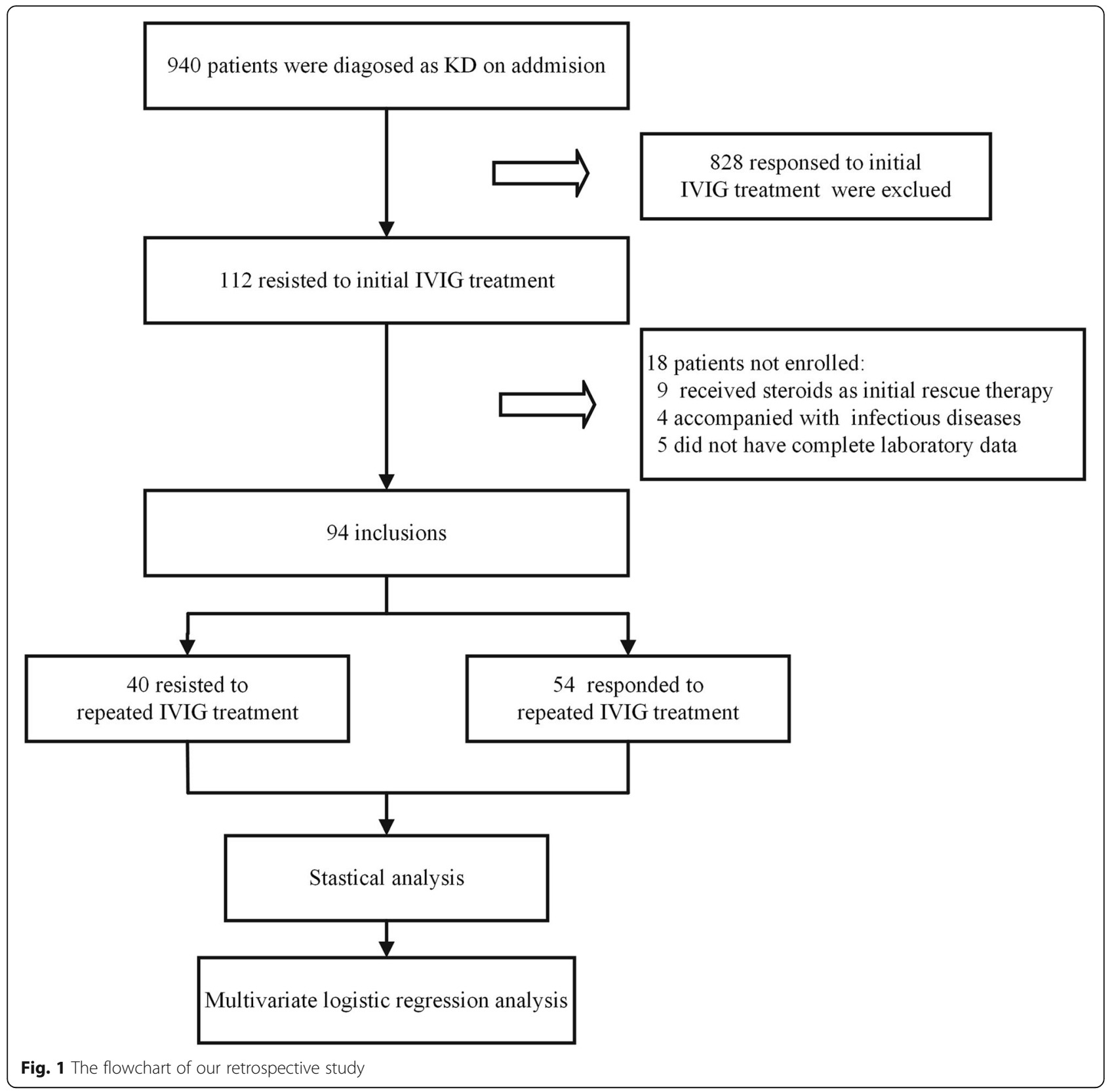

continuous variables are described as median with interquartile range (25-75\% percentile). All categorical variables are described as a frequency with percentage. A $\chi^{2}$ test was performed to compare categorical variables. Student's t-test was used for normally distributed continuous variables. The Mann-Whitney U-test was used when the distribution was skewed. Receiver operating characteristic curve (ROC) analysis for the predictor was performed, the sensitivity and specificity were calculated, and the cutoff value was determined by the Youden index. Multivariate logistic regression analyses were performed to determine predictors of repeated
IVIG resistance. Statistical significance was defined as a $P<0.05$.

\section{Results}

Table 1 exhibits clinical data of the repeated IVIGresponsive group and repeated IVIG-resistant group. The clinical variables of sex, age, the proportion of incomplete $\mathrm{KD}$, the incidence of $\mathrm{CAA}$, and the time of IVIG treatment showed no significant differences between the two groups $(P>0.05)$.

Table 2 exhibits pre-IVIG laboratory data. N\% and levels of serum PCT, NT-proBNP were significantly 
Table 1 Clinical data of the study subjects

\begin{tabular}{llll}
\hline Parameter & $\begin{array}{l}\text { repeated IVIG-responsive group } \\
(\boldsymbol{n}=\mathbf{5 4 )}\end{array}$ & $\begin{array}{l}\text { repeated IVIG-resistant group } \\
(\boldsymbol{n}=\mathbf{4 0})\end{array}$ \\
\hline Age(months) & $35.0(13.0 \sim 60.0)$ & $38.5(19.0 \sim 50.7)$ & $\boldsymbol{p}$ \\
Boys (\%) & $44(81.4 \%)$ & $26(65.0 \%)$ & $4(10.0 \%)$ \\
iKD[(\%)] & $4(7.4 \%)$ & $5.5(5.0 \sim 6.0)$ & 0.070 \\
Time of first IVIG (day) & $6.0(5.0 \sim 6.0)$ & $9.00(8.0 \sim 12.7)$ & 0.656 \\
Time of second IVIG (day) & $10.0(8.0 \sim 12.0)$ & $12(30.0 \%)$ & 0.535 \\
NO. of CAA before initial IVIG (\%) & $12(22.2 \%)$ & $14(35.0 \%)$ & 0.307 \\
NO. of CAA at discharge (\%) & $12(22.2 \%)$ & 0.393 \\
\hline
\end{tabular}

*Statistically significant $(P<0.05)$

IVIG intravenous immunoglobulin, iKD incomplete kawasaki disease, CAA coronary artery aneurysm, NO. number

higher in the repeated IVIG-resistant group compared with repeated IVIG-responsive group, while levels of serum $\mathrm{Na}+$ and ALB were significantly lower $(P<0.05)$. The ROC curves using pre-IVIG laboratory data of N\%, Na+, ALB, PCT and NTproBNP to predict repeated IVIG resistance were analyzed (Fig. 2; Table 3). Pre-IVIG PCT exhibited the largest AUC (0.751) compared with other indicators. According to the maximum Youden index, the classical cutoff points for PCT, N\%, Na+, ALB, and NT-
proBNP were $1.81 \mathrm{ng} / \mathrm{ml}, 133.8 \mathrm{mmol} / \mathrm{l}, 32.2 \mathrm{U} / \mathrm{L}$, $965.8 \mathrm{pg} / \mathrm{dl}$, respectively. The sensitivity of PCT was revealed to be the highest with a value of $80.0 \%$, and the specificity of NT-proBNP was determined to be the highest with a value of $85.1 \%$. Using $\mathrm{N} \%>76.5 \%, \quad \mathrm{Na}+\leq 133.8 \mathrm{mmol} / \mathrm{l}, \quad \mathrm{ALB} \leq 32.2 \mathrm{ng} / \mathrm{ml}$, PCT $>1.81 \mathrm{ng} / \mathrm{ml}$, NT-proBNP $>965.8 \mathrm{pg} / \mathrm{ml}$ before initial IVIG treatment as binary independent variable, multivariate logistic regression analysis for repeated IVIG resistance in KD was analyzed

Table 2 Laboratory data of the study subjects pre-IVIG treatment

\begin{tabular}{|c|c|c|c|}
\hline Parameter & $\begin{array}{l}\text { repeated IVIG-responsive group } \\
(n=54)\end{array}$ & $\begin{array}{l}\text { repeated IVIG-resistant group } \\
(n=40)\end{array}$ & $p$ \\
\hline$\overline{\text { WBC count }\left(\times 10^{9} / \mathrm{L}\right)}$ & $16.51(10.25 \sim 20.59)$ & $15.39(11.07 \sim 17.74)$ & 0.807 \\
\hline N\% & $73.50(70.50 \sim 86.60)$ & $84.60(74.97 \sim 89.15)$ & $0.017^{*}$ \\
\hline $\mathrm{Hb}(\mathrm{g} / \mathrm{L})$ & 110(96 121) & 103(92 115) & 0.061 \\
\hline $\operatorname{PLT}\left(\times 10^{9} / \mathrm{L}\right)$ & $284(215 \sim 381)$ & 264(190 339) & 0.173 \\
\hline $\mathrm{CRP}(\mathrm{mg} / \mathrm{L})$ & $106.5(73.0 \sim 141.0)$ & $114.0(83.8 \sim 166.5)$ & 0.119 \\
\hline $\mathrm{ESR}(\mathrm{mm} / \mathrm{h})$ & $81.0(52.0 \sim 100.0)$ & $86.5(65.8 \sim 119.5)$ & 0.338 \\
\hline ALT (U/L) & $61.4(17.0 \sim 153.6)$ & $66.0(28.0 \sim 136.9)$ & 0.482 \\
\hline AST (U/L) & $67.1(35.9 \sim 133.9)$ & $41.5(33.2 \sim 97.7)$ & 0.178 \\
\hline $\mathrm{Na}+(\mathrm{mmol} / \mathrm{L})$ & 135.0(133.8 137.8) & 133.0(130.3 136.9) & $0.006^{*}$ \\
\hline ALB $(\mathrm{g} / \mathrm{L})$ & $33.5(30.2 \sim 37.1)$ & $30.2(29.3 \sim 33.3)$ & $0.001^{*}$ \\
\hline TB (umol/L) & $12.6(9.8 \sim 17.8)$ & $14.9(11.4 \sim 18.9)$ & 0.167 \\
\hline Creatinine (umol/L) & $30.8(26.7 \sim 35.0)$ & $32(29.0 \sim 35.8)$ & 0.234 \\
\hline Urea nitrogen $(\mathrm{mmol} / \mathrm{L})$ & $3.19(2.79 \sim 3.49)$ & $3.33(2.83 \sim 3.90)$ & 0.063 \\
\hline APTT(s) & $47.8(43.5 \sim 52.5)$ & $44.6(41.2 \sim 52.5)$ & 0.351 \\
\hline $\mathrm{PT}(\mathrm{s})$ & $15.3(14.5 \sim 16.8)$ & $16.0(15.4 \sim 16.7)$ & 0.052 \\
\hline D-dimer (ug/ml) & $1.92(1.36 \sim 3.88)$ & $2.34(1.44 \sim 3.89)$ & 0.204 \\
\hline PCT (ng/ml) & $1.40(0.99 \sim 2.84)$ & $3.81(1.90 \sim 10.51)$ & $<0.001^{*}$ \\
\hline NT-proBNP(pg/ml) & $487.1(182.3 \sim 763.9)$ & $669.8(303.5 \sim 1493.8)$ & $0.015^{*}$ \\
\hline
\end{tabular}

*Statistically significant $(P<0.05)$

WBC white blood cell, $H b$ hemoglobin, $P L T$ platelet, N\% percentage of neutrophils, CRP C-reactive protein, ESR erythrocyte sedimentation rate, $A L T$ alanine aminotransferase, AST aspartate transaminase, $N a+$ serum sodium, $A L B$ albumin, $T B$ total bilirubin, APTT activated partial thromboplastin time, $P T$ prothrombin time, $P C T$ procalcitonin, NT-proBNP N-terminal pro-brain natriuretic peptide 


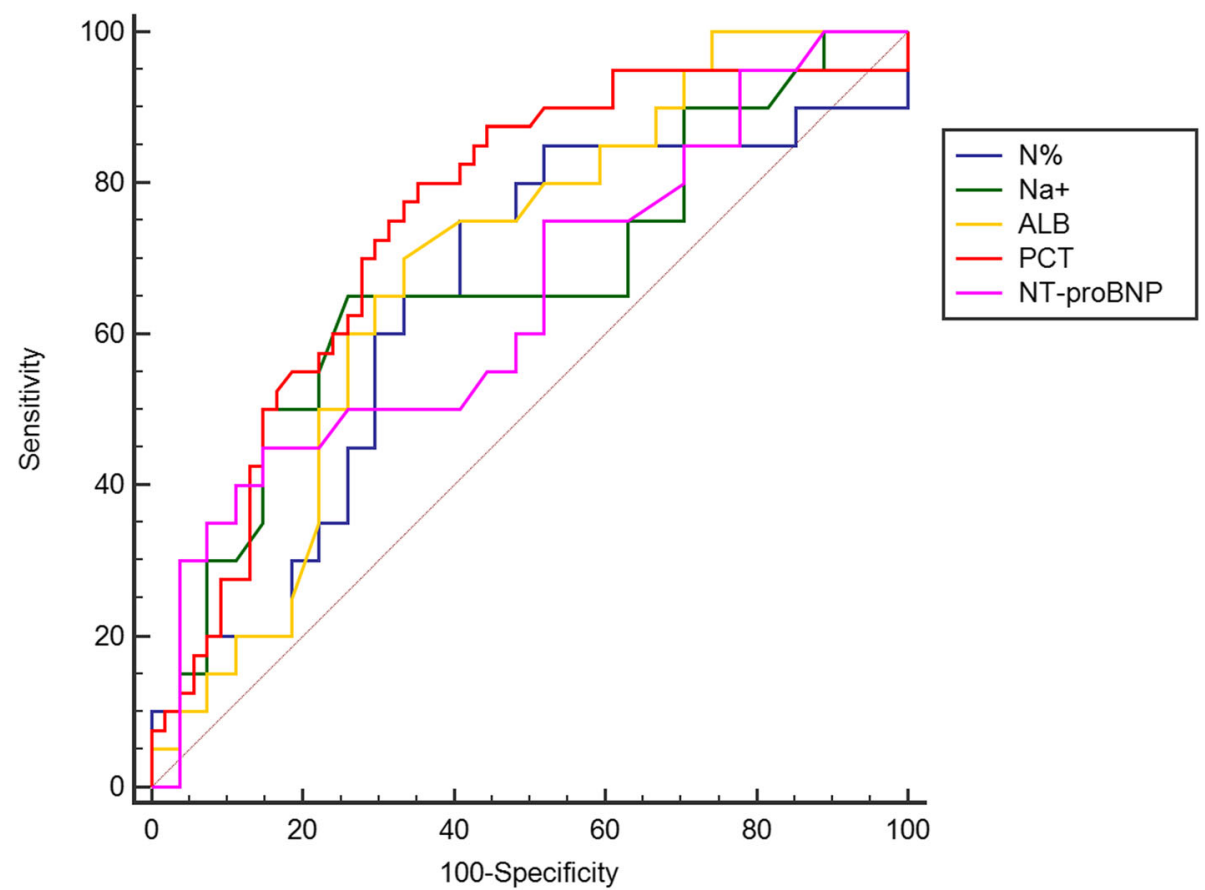

Fig. 2 ROC curve analysis of pre-IVIG laboratory data in predicting repeated IVIG resistanceN\%: percentage of neutrophils; Nat: serum sodium; ALB: albumin; PCT: procalcitonin; NT-proBNP: N-terminal pro-brain natriuretic peptide; AUC, area under curve

(Table 4). The results showed that pre-IVIG PCT > $1.81 \mathrm{ng} / \mathrm{ml}$ was an independent predictor for repeated IVIG resistance (OR 4.1, $95 \%$ CI $1.4 \sim 12.0, P<0.05$ ).

Table 5 exhibits post-IVIG laboratory data. N\% and CRP were significantly higher in the repeated IVIGresistant group compared with repeated IVIG-responsive group, while $\mathrm{Hb}$ and levels of serum ALB were significantly lower $(P<0.05)$. The ROC curves using post-IVIG laboratory data of $\mathrm{N} \%, \mathrm{Hb}, \mathrm{CRP}$, and ALB to predict repeated IVIG resistance were analyzed (Fig. 3; Table 6). Post-IVIG CRP exhibited the largest AUC (0.778) compared with other indicators. The classical cutoff points for $\mathrm{N} \%, \mathrm{Hb}, \mathrm{CRP}$, and ALB post IVIG were $62.5 \%, 97 \mathrm{~g} /$ $\mathrm{L}, 45.0 \mathrm{mg} / \mathrm{L}, 29.7 \mathrm{U} / \mathrm{L}$, respectively. The sensitivity of CRP was revealed to be the highest with a value of
$87.50 \%$. Using N\%>62.5\%, $\mathrm{Hb} \leq 97 \mathrm{~g} / \mathrm{L}, \mathrm{CRP}>45 \mathrm{mg} / \mathrm{L}$, $\mathrm{ALB} \leq 29.7 \mathrm{U} / \mathrm{L}$ post initial IVIG treatment as binary independent variable, multivariate logistic regression analysis for repeated IVIG resistance in KD was analyzed (Table 7). The results showed that post-IVIG CRP > $45 \mathrm{mg} / \mathrm{L}$ was an independent predictor (OR 4.6, $95 \% \mathrm{CI}$ $1.3 \sim 16.2, P<0.05)$.

\section{Discussion}

There have been numerous studies of initial IVIG resistance in KD, but few reports on repeated IVIG resistance. In our retrospective investigation, the incidence of initial IVIG resistance was about $11.9 \%(112 / 940)$, and the rate of repeated IVIG resistance was about $4.2 \%(40 / 940)$. It has been reported that age less than 3 months,

Table 3 ROC curve analysis of pre-IVIG laboratory data to predict repeated IVIG resistance

\begin{tabular}{llllllll}
\hline Indicator & AUC & $\boldsymbol{P}$-value & $\mathbf{9 5} \% \mathbf{C l}$ & Cut-off & Sensitivity (\%) & Specificity (\%) & Youden index \\
\hline N\% & 0.644 & 0.016 & $0.539 \sim 0.741$ & $76.5^{a}$ & 75.00 & 59.26 & 0.3426 \\
$\mathrm{Na}+$ & 0.667 & 0.005 & $0.562 \sim 0.761$ & $133.8^{\mathrm{b}}$ & 65.00 & 74.07 & 0.3907 \\
$\mathrm{ALB}$ & 0.690 & $<0.001$ & $0.586 \sim 0.781$ & $32.2^{\mathrm{c}}$ & 70.00 & 66.67 & 0.3667 \\
$\mathrm{PCT}$ & 0.751 & $<0.001$ & $0.710 \sim 0.879$ & $1.81^{\mathrm{d}}$ & 80.00 & 64.80 & 0.4481 \\
NT-proBNP & 0.647 & 0.012 & $0.542 \sim 0.743$ & $965.8^{\mathrm{e}}$ & 45.00 & 85.19 & 0.3019 \\
\hline
\end{tabular}

a Values are $\% ;^{\text {b }}$ Values are $\mathrm{mmol} / \mathrm{l}^{\mathrm{c}}$ Values are $\mathrm{U} / \mathrm{L} ;{ }^{\mathrm{d}}$ Values are $\mathrm{ng} / \mathrm{ml} ;{ }^{\mathrm{e}}$ Values are $\mathrm{pg} / \mathrm{ml}$

N\% percentage of neutrophils, Na+ serum sodium, ALB albumin, PCT procalcitonin, NT-proBNP N-terminal pro-brain natriuretic peptide, AUC area under curve 
Table 4 Multivariate logistic regression model composing preIVIG laboratory data for predicting repeated IVIG resistance

\begin{tabular}{llll}
\hline Indicator & $\boldsymbol{P}$ & $\boldsymbol{O} \boldsymbol{R}$ & $\mathbf{9 5} \% \mathbf{C l}$ \\
\hline $\mathrm{N} \%>76.5 \%$ & 0.179 & 2.183 & $0.699 \sim 6.815$ \\
$\mathrm{Na}+\leq 133.8 \mathrm{mmol} / \mathrm{l}$ & 0.421 & 1.611 & $0.504 \sim 5.153$ \\
$\mathrm{ALB} \leq 32.2 \mathrm{ng} / \mathrm{ml}$ & 0.146 & 2.226 & $0.758 \sim 6.541$ \\
$\mathrm{PCT}>1.81 \mathrm{ng} / \mathrm{ml}$ & 0.008 & 4.161 & $1.441 \sim 12.017$ \\
$\mathrm{NT}-$ proBNP $>965.8 \mathrm{pg} / \mathrm{ml}$ & 0.177 & 2.281 & $0.690 \sim 7.541$ \\
\hline
\end{tabular}

$N \%$ percentage of neutrophils, $N a+$ serum sodium, $A L B$ albumin, $P C T$ procalcitonin, NT-proBNP N-terminal pro-brain natriuretic peptide, $A U C$ area under curve

incomplete $\mathrm{KD}$, incidence of CAA and initial administration of IVIG $\leq 4.0$ days were associated with initial IVIG resistance $[15,16]$. But, these clinical data were not associated with repeated IVIG resistance in our research. The hypercoagulation of increased APTT, PT and Ddimer and the abnormal liver function of increased ALT, AST, TB were confirmed as the risk factors favor initial IVIG resistance $[17,18]$. These laboratory data failed to be the predictor of repeated IVIG resistance in our study, which was not found in other studies either [18, 19].

However, pre-IVIG laboratory data showed that KD children with repeated IVIG resistance had higher $\mathrm{N} \%, \mathrm{PCT}$, and lower ALB, Na+ compared with KD children responding to repeated IVIG treatment, which is also confirmed in other studies [12, 17, 20], indicating more serious inflammation and increased vascular permeability after KD onset in these children [21]. A significantly higher level of NT-proBNP, which is an important cardiac biomarker that associating with ventricular myocyte ischemia and hypoxia [22], was observed in these children, indicating more serious myocardial injury. Among the post-IVIG laboratory data, values of N\% and CRP were higher in the repeated IVIG-resistant group, while $\mathrm{Hb}$ and ALB were lower, indicating more inadequate remission of systemic inflammation and vasculitis in children with repeated IVIG resistance after initial IVIG treatment, that may require more aggressive rescue therapy than IVIG alone.

Predictive values of pre- and post-IVIG laboratory data on repeated IVIG resistance were further explored respectively. The pre-IVIG regression model showed PCT $>1.81 \mathrm{ng} / \mathrm{ml}$ before initial IVIG treatment was an independent predictor of repeated IVIG resistance in KD. Comparing with CRP as well as the other inflammation indicator, PCT may reflect uncontrollable hypercytokinemia faster along with the involvement of TNF- $\alpha$ signaling pathway in KD, based on the characteristics of early elevation and shorter half time [23]. Pre-IVIG NT-proBNP yielded the highest specificity, but it failed to predict repeated IVIG resistance, the reason may be due to relatively low sensitivity of $45.00 \%$. At its root, perhaps, the mechanism of IVIG resistance is an immune response that causes systemic vasculitis, not only damage to the coronary arterial wall [24]. The increase of PCT in monocytes and granulocytes mediated by the activated innate immune system after $\mathrm{KD}$ onset through tumor necrosis factor (TNF) signaling pathways could lead to impairing of endothelial cell $[25,26]$, which may relate to the etiology of Kawasaki disease. Though CRP has been known to reflect the extent of systemic inflammation and vasculitis, it alone does not always reflect the severity of $\mathrm{KD}$ or the treatment response of IVIG [20]. CRP $>45 \mathrm{mg} / \mathrm{L}$ after initial IVIG exhibited predictive value of repeated IVIG resistance in post-IVIG regression model. Persistently elevated CRP after initial IVIG may suggest a poorly responding severe form of $\mathrm{KD}$, that was found in other studies also [27].

Table $\mathbf{5}$ Laboratory data of the study subjects post-IVIG treatment

\begin{tabular}{llll}
\hline Parameter & $\begin{array}{l}\text { repeated IVIG-responsive group } \\
(\boldsymbol{n}=\mathbf{5 4})\end{array}$ & $\begin{array}{l}\text { repeated IVIG-resistant group } \\
(\boldsymbol{n}=\mathbf{4 0})\end{array}$ & $\boldsymbol{p}$ \\
\hline WBC count $\left(\times 10^{9} / \mathrm{L}\right)$ & $14.26(12.93 \sim 15.66)$ & $14.03(9.96 \sim 16.19)$ & 0.125 \\
$\mathrm{~N} \%$ & $62.50(59.50 \sim 75.60)$ & $74.40(64.77 \sim 78.95)$ & $0.008^{*}$ \\
$\mathrm{Hb}(\mathrm{g} / \mathrm{L})$ & $105(93 \sim 116)$ & $96(85 \sim 107)$ & $0.004^{*}$ \\
$\mathrm{PLT}\left(\times 10^{9} / \mathrm{L}\right)$ & $370(295 \sim 461)$ & $354(280 \sim 429)$ & 0.253 \\
$\mathrm{CRP}(\mathrm{mg} / \mathrm{L})$ & $41.0(27.3 \sim 65.8)$ & $76.0(50.0 \sim 124.0)$ & $<0.001^{*}$ \\
ALT $(\mathrm{U} / \mathrm{L})$ & $46.4(14.6 \sim 138.6)$ & $56.0(23.0 \sim 122.4)$ & 0.763 \\
AST $(\mathrm{U} / \mathrm{L})$ & $57.1(28.7 \sim 123.9)$ & $33.0(25.1 \sim 89.7)$ & 0.081 \\
ALB $(\mathrm{g} / \mathrm{L})$ & $31.2(28.6 \sim 33.1)$ & $29.4(27.6 \sim 31.5)$ & $0.010^{*}$ \\
\hline
\end{tabular}

*Statistically significant $(P<0.05)$

WBC white blood cell, N\%: percentage of neutrophils, $\mathrm{Hb}$ hemoglobin, PLT platelet, CRP C-reactive protein, $A L T$ alanine aminotransferase, $A S T$ aspartate transaminase, $A L B$ albumin 


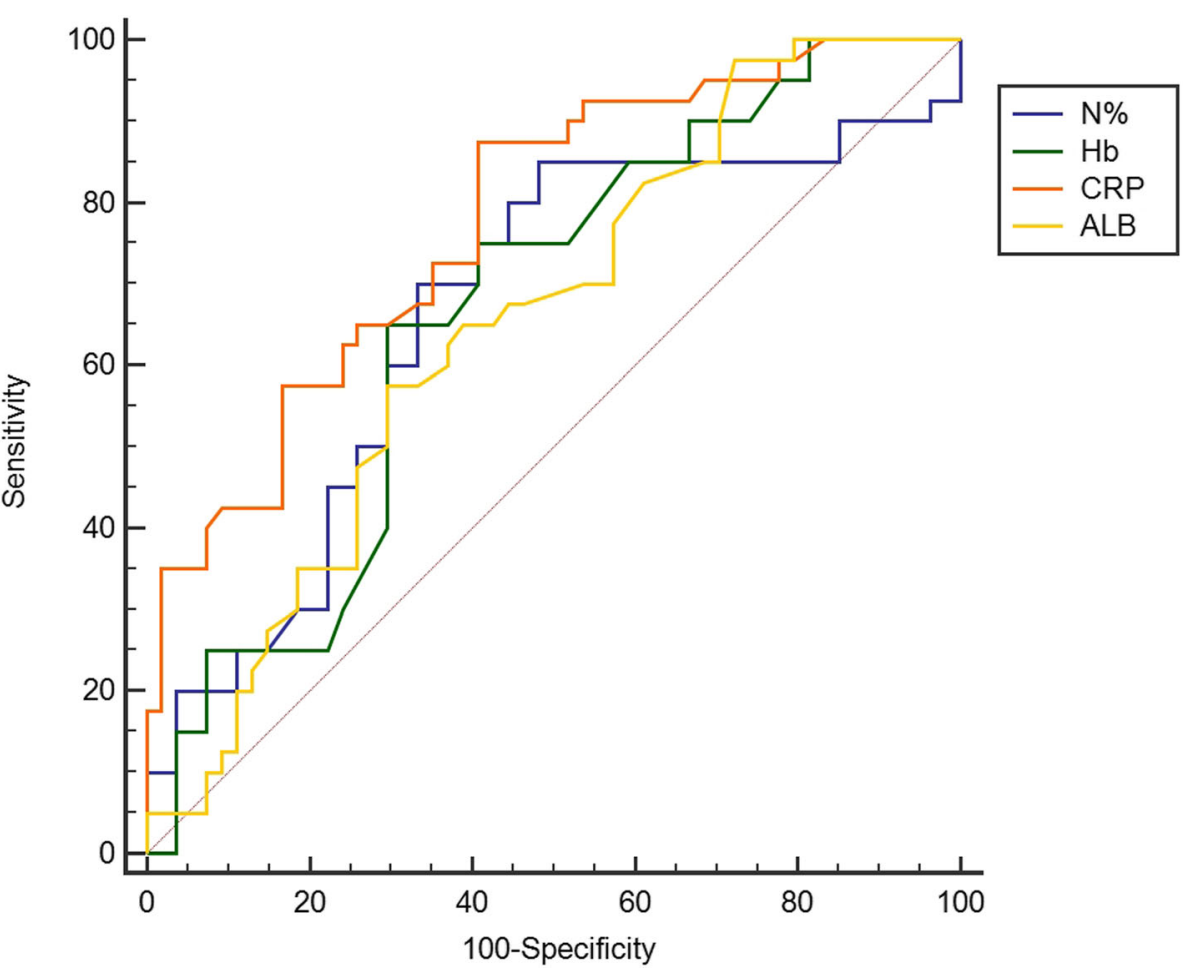

Fig. 3 ROC curve analysis of post-IVIG laboratory data in predicting repeated IVIG resistanceN\%: percentage of neutrophils; Hb: hemoglobin; CRP: C-reactive protein; ALB: albumin

At present, whether enhancing anti-inflammatory treatment to reduce IVIG-resistance could decrease the incidence of CAA remains controversial [28]. In our study, the incidence of CAA during hospitalization was relatively higher in KD children with repeated IVIG resistance, indicating the potential benefit. Pulse intravenous methylprednisolone (PSL) (10-30 $\mathrm{mg} / \mathrm{kg} /$ day for three consecutive days) followed by oral prednisone ( $2 \mathrm{mg} / \mathrm{kg} /$ day) tapered over seven days was given to KD children with repeated IVIG resistance in our study, and all of them were relieved effectively. No patients received any additional treatment such as infliximab, plasma exchange, or cyclosporine. Recent studies demonstrated the IVIG plus PSL regimen as initial therapy for severe
KD or rescue therapy following resistance to initial IVIG was more effective in terms of achieving defervescence than IVIG alone $[29,30]$. Based on the predictor in our research, IVIG plus PSL as initial therapy for KD children with Pre-IVIG PCT $>1.81 \mathrm{ng} / \mathrm{ml}$ and as initial rescue therapy for KD children with post-IVIG CRP > $45 \mathrm{mg} / \mathrm{L}$ may be a reasonable intensified treatment strategy to reduce initial or repeated IVIG resistance respectively.

This study has some limitations. First, the sample size of this study is small, further multicenter prospective studies are needed to confirm our findings. Second, the present study had strict inclusion and exclusion criteria. The findings in our study were

Table 6 ROC curve analysis of post-IVIG laboratory data to predict repeated IVIG resistance

\begin{tabular}{llllllll}
\hline Indicator & AUC & P-value & $\mathbf{9 5} \% \mathbf{C l}$ & Cut-off & Sensitivity (\%) & Specificity (\%) & Youden index \\
\hline N\% & 0.665 & 0.005 & $0.560 \sim 0.759$ & $62.5^{\mathrm{a}}$ & 85.00 & 51.85 & 0.3685 \\
$\mathrm{Hb}$ & 0.667 & 0.003 & $0.562 \sim 0.761$ & $97^{\mathrm{b}}$ & 65.00 & 70.37 & 0.3537 \\
$\mathrm{CRP}$ & 0.778 & $<0.001$ & $0.680 \sim 0.857$ & $45.0^{\mathrm{c}}$ & 87.50 & 59.26 & 0.4676 \\
$\mathrm{ALB}$ & 0.652 & 0.007 & $0.547 \sim 0.747$ & $29.7^{\mathrm{d}}$ & 57.50 & 70.37 & 0.2787 \\
\hline
\end{tabular}

a Values are $\% ;{ }^{\text {b }}$ Values are $\mathrm{g} / \mathrm{L} ;{ }^{\mathrm{c}}$ Values are $\mathrm{mg} / \mathrm{L} ;{ }^{\mathrm{d}}$ Values are $\mathrm{U} / \mathrm{L}$

$N \%$ percentage of neutrophils, $H b$ hemoglobin, $C R P$ C-reactive protein, $A L B$ albumin 
Table 7 Multivariate logistic regression model composing postIVIG laboratory data for predicting repeated IVIG resistance

\begin{tabular}{llll}
\hline Indicator & $\boldsymbol{P}$ & $\mathbf{O R}$ & $\mathbf{9 5} \% \mathbf{C l}$ \\
\hline $\mathrm{N} \%>62.5 \%$ & 0.173 & 2.290 & $0.696 \sim 7.538$ \\
$\mathrm{Hb} \leq 97 \mathrm{~g} / \mathrm{L}$ & 0.205 & 1.949 & $0.694 \sim 5.476$ \\
$\mathrm{CRP}>45 \mathrm{mg} / \mathrm{L}$ & 0.016 & 4.664 & $1.339 \sim 16.247$ \\
$\mathrm{ALB} \leq 29.7 \mathrm{U} / \mathrm{L}$ & 0.174 & 1.973 & $0.740 \sim 5.256$ \\
\hline
\end{tabular}

$N \%$ percentage of neutrophils, $H b$ hemoglobin, CRP C-reactive protein, $A L B$ albumin

only applicable to KD patients receiving standardized IVIG treatment. Third, the parameter of post-IVIG laboratory data in our study was limited, more indicators need to be included prospectively. Fourth, every subject in this study was Chinese. Therefore, our findings should be examined in other ethnic groups.

\section{Conclusions}

KD children with repeated IVIG resistance have more serious inflammation and myocardial injury compared with KD children responding to repeated IVIG treatment. KD patients with PCT $>1.81 \mathrm{ng} / \mathrm{ml}$ before initial IVIG treatment and CRP $>45 \mathrm{mg} / \mathrm{L}$ after initial IVIG might be at higher risk of developing repeated IVIG resistance, which may require an early-intensified therapy.

\section{Abbreviations}

KD: Kawasaki disease; IVIG: Intravenous immunoglobulin; CAA: Coronary artery aneurysm; N\%: Percentage of neutrophils; ALB: Albumin; Na+: Serum sodium; PCT: Procalcitonin; NT-proBNP: N-terminal pro-brain natriuretic peptide; Hb: hemoglobin; CRP: C-reactive protein

\section{Acknowledgements}

The authors acknowledge Prof. Xianmin Wang, Women's and children's Hospital affiliated to Chengdu Medical College, Sichuan Women's and Children's Hospital, China, for reviewing this manuscript.

\section{Authors' contributions \\ Yaheng LU and Yanfeng Yang provided study conception and design, wrote the first draft of the manuscript. Tingting Chen, Yizhou Wen, Feifei Si and Xindan Wu provided data collection and statistical analysis. All authors have revised and edited the manuscript and accepted the final version of the manuscript. The author(s) read and approved the final manuscript.}

\section{Funding}

This study was funded by the Municipal Planning Commission of Science and Research Fund in Sichuan, China (17PJ270). The funders had no role in study design, data collection and analysis, decision to publish, or preparation of the manuscript.

\section{Availability of data and materials}

The datasets used and analyzed during the current study are not publicly available due to limitations of ethical approval involving the patient data and anonymity but are available from the corresponding author on reasonable request.

\section{Declarations}

\section{Ethics approval and consent to participate}

This retrospective study is approved by the Ethics Committee of Chengdu Women's and Children's Central Hospital, School of Medicine, UESTC, and with the 1964 Helsinki declaration and its later amendments or comparable ethical standards. Due to the retrospective nature of the study, informed consent was waived.

\section{Consent for publication}

Not Applicable.

\section{Competing interests}

The authors declare that they have no conflict of interest.

Received: 27 April 2021 Accepted: 2 September 2021

Published online: 16 September 2021

\section{References}

1. McCrindle BW, Rowley AH, Newburger JW, Burns JC, Bolger AF, Gewitz M, et al. Diagnosis, treatment, and long-term management of Kawasaki disease: a scientific statement for health professionals from the American Heart Association. Circulation. 2017; 135(17):e927-e99.

2. Duignan S, Doyle SL, McMahon CJ. Refractory Kawasaki disease: diagnostic and management challenges. Pediatric Health Med Ther. 2019; 10:131-9.

3. Song R, Yao W, Li X. Efficacy of four scoring systems in predicting intravenous immunoglobulin resistance in children with kawasaki disease in a children's hospital in Beijing, north China. J Pediatr. 2017; 184:120-4.

4. Fukazawa R, Kobayashi J, Ayusawa M, Hamada H, Miura M, Mitani Y, et al. JCS/JSCS 2020 Guideline on diagnosis and management of cardiovascular sequelae in Kawasaki disease. Circ J. 2020; 84(8):1348-1407.

5. Phuong LK, Curtis N, Gowdie P, Akikusa J, Burgner D. Treatment options for resistant Kawasaki disease. Paediatr Drugs. 2018; 20(1):59-80.

6. Son MB, Gauvreau K, Ma L, Baker AL, Sundel RP, Fulton DR, et al. Treatment of Kawasaki disease: analysis of 27 US pediatric hospitals from 2001 to 2006 Pediatrics. 2009; 124(1):1-8.

7. Dionne A, Burgner D, De Ferranti S, Singh-Grewal D, Newburger J, Dahdah N. Variation in the management of Kawasaki disease. Arch Dis Child. 2020; 105(10):1004-6.

8. Chan $\mathrm{H}$, Chi $\mathrm{H}$, You H, Wang $\mathrm{M}$, Zhang $\mathrm{G}$, Yang $\mathrm{H}$, et al. Indirect-comparison meta-analysis of treatment options for patients with refractory Kawasaki disease. BMC Pediatr. 2019: 19(1):158.

9. Roberts SC, Jain S, Tremoulet AH, Kim KK, Burns JC, KIDCARE Multicenter Study Group, et al. The Kawasaki Disease Comparative Effectiveness (KIDC ARE) trial: A phase III, randomized trial of second intravenous immunoglobulin versus infliximab for resistant Kawasaki disease. Contemp Clin Trials. 2019; 79:98-103.

10. Dionne A, Bucholz EM, Gauvreau K. Impact of socioeconomic status on outcomes of patients with Kawasaki disease. J Pediatr. 2019; 212:87-92.

11. Kimura M, Harazaki M, Fukuoka T, Asakura I, Sakai H, Kamimaki T, et al. Targeted use of prednisolone with the second IVIG dose for refractory Kawasaki disease. Pediatr Int. 2017; 59(4):397-403.

12. Shao S, Luo C, Zhou K, Hua Y, Wu M, Liu L, et al. Predictive value of serum procalcitonin for both initial and repeated immunoglobulin resistance in Kawasaki disease: a prospective cohort study. Pediatr Rheumatol Online J. 2019; 17(1):78

13. McCrindle BW, Li JS, Minich LL, Colan SD, Atz AM, Takahashi M, et al. Coronary artery involvement in children with Kawasaki disease: risk factors from analysis of serial normalized measurements. Circulation. 2007; 116(2): 174-9.

14. Newburger JW, Takahashi M, Gerber MA, Gewitz MH, Tani LY, Burns JC, et al. Diagnosis, treatment, and long-term management of Kawasaki disease: a statement for health professionals from the committee on rheumatic fever, endocarditis and Kawasaki disease, council on cardiovascular disease in the young, American Heart Association. Circulation. 2004; 110(17):2747-71.

15. Chuang $\mathrm{CH}$, Hsiao MH, Chiu CH, Huang YC, Lin TY. Kawasaki disease in infants three months of age or younger. J Microbiol Immunol Infect. 2006; 39(5):387-391.

16. Jaggi P, Grcic M, Kovalchin J, Wilhelm CM, Yildirim-Toruner C, Texter K. Using the electronic medical record to correlate Kawasaki disease phenotypes with clinical outcomes. J Pediatric Infect Dis Soc. 2018; 7(2): 119-23.

17. Shao S, Yang L, Liu X, Liu L, Wu M, Deng Y, et al. Predictive value of coagulation profiles for both initial and repeated immunoglobulin resistance in Kawasaki disease: A prospective cohort study. Pediatr Allergy Immunol. 2021; 00:1-11. 
18. Liu L, Yin W, Wang R, Sun D, He X, Ding Y. The prognostic role of abnormal liver function in IVIG unresponsiveness in Kawasaki disease: a meta-analysis. Inflamm Res. 2016; 65(2):161-8.

19. Seo E, Yu JJ, Jun HO, Shin EJ, Baek JS, Kim YH, et al. Prediction of unresponsiveness to second intravenous immunoglobulin treatment in patients with Kawasaki disease refractory to initial treatment. Korean J Pediatr. 2016; 59(10):408-13.

20. Liu X, Wang L, Zhou K, Shao S, Hua Y, Wu M, et al. Predictive value of Creactive protein to albumin ratio as a biomarker for initial and repeated intravenous immunoglobulin resistance in a large cohort of Kawasaki disease patients: a prospective cohort study. Pediatr Rheumatol Online J. 2021; 19(1):24

21. Taddio A, Rossi ED, Monasta L, Pastore S, Tommasini A, Lepore L, et al. Describing Kawasaki shock syndrome: results from a retrospective study and literature review. Clin Rheumatol. 2017: 36(1):223-28.

22. Sato YZ, Molkara DP, Daniels LB, Tremoulet AH, Shimizu C, Kanegaye JT, et al. Cardiovascular biomarkers in acute Kawasaki disease. Int J Cardiol. 2013; 164(1):58-63.

23. Nakashima Y, Nanishi E, Yamamura K, Uike K, Terashi E, Hirata Y, et al. Procalcitonin levels predicting the infliximab response of immunoglobulin resistant Kawasaki disease. Cytokine. 2019; 114: 26-31.

24. Marrani E, Burns JC, Cimaz R. How should we classify Kawasaki disease? Front Immunol. 2018; 9:2974.

25. Wagner NM, Van Aken C, Butschkau A, Bierhansl L, Kellner P, Schleusener V, et al. Procalcitonin impairs endothelial cell function and viability. Anesth Analg. 2017; 124(3):836-45.

26. Wang Y, Qian SY, Yuan Y, Wang Q, Gao L, Chen X, et al. Do cytokines correlate with refractory Kawasaki disease in children? Clin Chim Acta. 2020; 506: 222-7.

27. Nakagama Y, Inuzuka R, Hayashi T, Shindo T, Hirata Y, Shimizu N, et al. Fever pattern and C-reactive protein predict response to rescue therapy in Kawasaki disease. Pediatr Int. 2016; 58(3):180-4.

28. Okubo Y, Miura M, Kobayashi T, Morisaki N, Michihata N, Matsui H, et al. The impact of changes in clinical guideline on practice patterns and healthcare utilizations for Kawasaki disease in japan. Front Pediatr. 2020; 8:114.

29. Kobayashi T, Saji T, Otani T, Takeuchi K, Nakamura T, Arakawa H, et al. Efficacy of immunoglobulin plus prednisolone for prevention of coronary artery abnormalities in severe Kawasaki disease (RAISE study): a randomised, open-label, blinded-endpoints trial. Lancet. 2012; 379(9826):1613-20

30. Kobayashi T, Kobayashi T, Morikawa A, Ikeda K, Seki M, Shimoyama S, et al. Efficacy of intravenous immunoglobulin combined with prednisolone following resistance to initial intravenous immunoglobulin treatment of acute Kawasaki disease. J Pediatr. 2013; 163(2):521-6.

\section{Publisher's Note}

Springer Nature remains neutral with regard to jurisdictional claims in published maps and institutional affiliations.

Ready to submit your research? Choose BMC and benefit from:

- fast, convenient online submission

- thorough peer review by experienced researchers in your field

- rapid publication on acceptance

- support for research data, including large and complex data types

- gold Open Access which fosters wider collaboration and increased citations

- maximum visibility for your research: over $100 \mathrm{M}$ website views per year

At $\mathrm{BMC}$, research is always in progress.

Learn more biomedcentral.com/submissions 